\title{
Comparing two computer search models for aggregate production planning
}

\author{
J.T. Meij \\ Department of Industrial Engineering, University of Stellenbosch
}

\begin{abstract}
In this paper a comparison is made between the results and the cost-effectiveness of two computer search models for ag. gregate production planning when applied to a very sensitive high-order cost structure. The Search Decision Rule (SDR) model developed by Taubert outperforms the Sectioning Search Model (SECT) of Goodman in both the areas of total optimum cost. and cost-effectiveness.

S. Afr. J. Bus. Mgmt. 1982, 13: $67-69$
\end{abstract}

In hierdie artikel word ' $n$ vergelyking getref tussen die resultate en die koste-doeltreffendheid van twee rekenaar. soekmodelle vir geheelskedule-produksiebeplanning, soos toegepas op 'n baie sensitiewe hoë-orde kostestruktuur. Die 'Search Decision Rule'-model (SDR) ontwikkel deur Taubert lewer in albei areas, naamlik totale optimale koste en kostedoeltreffendheid, beter resultate as die 'Sectioning Search Model' (SECT) van Goodman.

S.Afr. Tydskr. Bedryfsl. 1982, 13: $67-69$

Second in a series of three articles

\section{Introduction}

Many production managers are faced with the problem of planning production, inventory and work force under the constraint of limited recources to meet a seasonal demand. In those cases where linearity of the cost functions of an undertaking may reasonably be assumed, an ordinary linear programming model suffices. In many cases, however, this simple linear approach to certain essentially non-linear cost functions is unacceptable owing to the gross approximation made. Considerable research has been done on this planning problem and various models have been proposed. These models can be divided into three broad categories, namely heuristic models, mathematical optimization models and computer search models.

In this paper a comparison is made between the results of two of the published computer search models on a high-order cost function. One of the following four basic strategies can be followed to meet the fluctuations in demand.

1. Work-force level and production rate are kept constant and inventory is used to absorb fluctuations in demand.

2. Work-force level and inventory are kept constant and demand fluctuations are handled by changing the production rate, i.e. working overtime or allowing idle time.

3. Production rate and inventory are kept constant and the work force is varied to suit the demand.

4. A combination of the three strategies given above.

In most cases in industry the combination type of strategy (4) is usually the most appropriate. The extent to which the different strategies should be mixed to present an overall plan is dependent on the cost structure of the particular industry.

Cost structures vary, and may have anything from linear or almost linear, to highly non-linear relationships. In many cases ordinary linear or piecewise linear functions may be adequate to describe the relationship between cost and one of the above-mentioned variables. On the other hand it may well be that for certain costs a linear approach is unrealistic and far removed from the real world situation. In the latter case it becomes extremely difficult to obtain a proven optimum solution. Various methods have been suggested to solve this problem.

For a solution method to be practical it must comply 
with the following primary properties:

- It must be cost effective.

- It must assure, with reasonable confidence, that a global optimum will be reached.

- It must be universally applicable.

With the development of the high-speed digital computer, computer search methods have been developed and implemented to comply, in the field of aggregate production planning, with these properties. Taubert' compared various search algorithms and found the HookeJeeves algorithm ${ }^{2}$ particularly suitable for the solution of high-order functions. He made use of this algorithm in the development of his computer search system, Search Decision Rule (SDR). Goodman ${ }^{3}$ applied a modified Sectioning Search Model (SECT) to a high-order cost function.

The author applied the SDR model to the high-order cost function used by Goodman and compared the results with those of the SECT.

\section{Description of the cost structure}

In order to test the Sectioning Search Model, Goodman developed a fourth-order cost model. The real world costs, of which this model is an approximation, are given in Table 1. The cost components considered in this model are: direct payroll, overtime and idle time, hiring and layoff, change of production rate and inventory holding and shortages. The objective cost function to be minimized is:

$$
\begin{aligned}
C=\sum_{t=1}^{N}[ & 340 W_{t}+0,2\left(P_{t}-6 W_{t}\right)^{4} \\
& +64\left(W_{t}-W_{t-1}\right)^{4}+0,1\left(P_{t}-P_{t-1}\right)^{4} \\
& \left.+0,1\left(320-I_{l}\right)^{4}\right]
\end{aligned}
$$

Where $W$, is the work force in period $t$, $P_{t}$ is the production in period $t$, and $I$, is the inventory in period $t$;

subject to the following constraints:

$$
\begin{array}{ll}
I_{t}=I_{t-1}+P_{t}-D_{,} & (t=1 \text { to } N) \\
O \leqslant W_{t} \leqslant 150 & (t=1 \text { to } N)
\end{array}
$$

$$
0 \leqslant P_{1} \leqslant 1000 \quad(t=1 \text { to } N)
$$

where $D$, is the demand in period $t$.

Work force and production quantity in each period are the independent variables. From these variables, as well as the given demand $\left(D_{1}\right)$, the other variable contributing to the cost, that is inventory, is calculated.

\section{Results}

In Table 2 the monthly production plans and corresponding costs given by SDR and SECT are compared for a 24-month planning horizon. SDR gave an improvement of nearly $6 \%$ on the total cost of $\$ 14196488$ obtained by Goodman's SECT. It can also be seen that the cost model is very sensitive to small changes in any of the variables - compare for example the monthly costs for months 3 (SECT 53\% higher than SDR), 4 (SECT 52\% higher than SDR) and 8 (SECT $52 \%$ higher than SDR). There are no major differences between the two plans. From a practical point of view any one of the two plans could be adopted. It must thus be emphasized that for highlysensitive cost structures as the one used here, extreme care must be taken in the choice of an optimization method.

To measure the cost-efficiency of the two search techniques, the computer time required per decision (independent variable) is compared. It should be kept in mind, however, that as Goodman states, ' . . . computer time usage is a function of both the computer used and programming efficiency and method used'. ${ }^{3}$ He states that on average the Sectioning Search Model uses 0,75 s per decision. It was found that SDR used only $0,38 \mathrm{~s}$ per decision on a UNIVAC 1110 computer. By decreasing the number of search repetitions of the SDR procedure, a plan was obtained using only $0,24 \mathrm{~s}$ per decision (a $68 \%$ saving in computer time). The total cost of this plan was only $0,14 \%$ higher than the results previously obtained.

\section{Conclusion}

In this paper a comparison is made between the results of two well-known search models developed for aggregate production planning. For comparison purposes a highorder cost model has been used. The SDR-model of Taubert outperforms the SECT-model of Goodman when compared on the basis of total optimum cost and cost-effectiveness.

Table 1 Real world cost on which the cost model is based (Rand)

\begin{tabular}{crrrrrrr}
\hline$\left|W_{t}-W_{t-1}\right|$ & Cost & $\left|P_{t}-P_{t}\right|$ & \multicolumn{1}{c}{ Cost } & $\left|I_{t}-320\right|$ & Cost & $\left|P_{t}-6 W_{t}\right|$ & Cost \\
\hline 0 & 0 & 1 & 1 & 1 & 1 & 0 & 0 \\
1 & 66 & 2 & 2 & 2 & 2 & 1 & 1 \\
2 & 1001 & 4 & 24 & 3 & 9 & 2 & 4 \\
3 & 5210 & 5 & 68 & 4 & 28 & 3 & 14 \\
4 & 20100 & 7 & 225 & 6 & 122 & 5 & 131 \\
5 & 38120 & 10 & 1049 & 8 & 392 & 7 & 457 \\
7 & 86300 & 16 & 6310 & 11 & 1370 & 10 & 1876 \\
9 & 139200 & 22 & 26100 & 15 & 5417 & 12 & 3780 \\
12 & 224400 & 34 & 123400 & 21 & 18240 & 14 & 7795 \\
14 & 279600 & 52 & 487200 & 39 & 231200 & 18 & 20600 \\
19 & 401100 & 87 & 1140000 & 51 & 474400 & 22 & 34900 \\
25 & 698700 & 150 & 2224000 & 70 & 762500 & 30 & 58200 \\
\hline
\end{tabular}


Table 2 Production plans, Search Decision Rule (SDR) and Sectioning Search (SECT)

\begin{tabular}{cccccccccrr}
\hline & \multicolumn{9}{c}{ Work force } & \multicolumn{2}{c}{ Production } & \multicolumn{2}{c}{ Inventory } & \multicolumn{2}{c}{ Period cost } \\
Period & Demand & SDR & SECT & SDR & SECT & SDR & SECT & SDR & SECT \\
& & & & & & & & (Rand) & (Rand) \\
\hline 1 & 430 & 73 & 75 & 447 & 431 & 337 & 301 & 36205 & 160572 \\
2 & 447 & 70 & 72 & 431 & 440 & 321 & 294 & 36187 & 76836 \\
3 & 440 & 67 & 69 & 406 & 426 & 287 & 280 & 182702 & 392632 \\
4 & 316 & 64 & 65 & 376 & 392 & 347 & 356 & 163305 & 340082 \\
5 & 397 & 62 & 62 & 362 & 374 & 312 & 333 & 29178 & 39620 \\
6 & 375 & 60 & 59 & 352 & 348 & 289 & 306 & 109783 & 75042 \\
7 & 292 & 62 & 60 & 364 & 348 & 361 & 362 & 305626 & 335780 \\
8 & 458 & 64 & 63 & 395 & 386 & 298 & 290 & 151989 & 316936 \\
9 & 400 & 63 & 64 & 383 & 391 & 281 & 281 & 244834 & 253710 \\
10 & 350 & 61 & 61 & 353 & 355 & 284 & 286 & 273730 & 330447 \\
11 & 284 & 63 & 63 & 359 & 356 & 359 & 358 & 278352 & 277808 \\
12 & 400 & 68 & 68 & 399 & 399 & 358 & 357 & 532877 & 593728 \\
13 & 483 & 73 & 73 & 442 & 444 & 317 & 318 & 414825 & 475143 \\
14 & 509 & 78 & 78 & 477 & 481 & 285 & 290 & 362126 & 340645 \\
15 & 500 & 83 & 83 & 491 & 488 & 276 & 278 & 432210 & 381629 \\
16 & 475 & 88 & 88 & 510 & 508 & 311 & 311 & 103618 & 118576 \\
17 & 500 & 94 & 94 & 553 & 552 & 364 & 363 & 853346 & 835740 \\
18 & 600 & 101 & 101 & 608 & 607 & 372 & 370 & 1752367 & 1728065 \\
19 & 700 & 107 & 107 & 662 & 662 & 334 & 332 & 1090724 & 1068460 \\
20 & 700 & 112 & 112 & 698 & 699 & 332 & 331 & 315675 & 373248 \\
21 & 725 & 107 & 107 & 658 & 659 & 265 & 265 & 1273906 & 1264146 \\
22 & 600 & 101 & 101 & 600 & 600 & 265 & 265 & 2171033 & 2244341 \\
23 & 432 & 95 & 95 & 545 & 545 & 378 & 378 & 2222244 & 2240081 \\
24 & 615 & 93 & 93 & 552 & 553 & 315 & 316 & 32637 & 33204 \\
Total cost & & & & & & & & 13368479 & 14196458 \\
\hline & & & & & & & & & &
\end{tabular}

\section{References}

1. Taubert, W.H. A search decision rule for the aggregate scheduling problem, Manage. Sci., Feb. 1968, 14(6), pp. B343-B359.

2. Hooke, R. \& Jeeves, T.A. 'Direct Search' solution of numerical and statistical problems, J. Assoc. Comp., April 1961, pp. $212-229$.

3. Goodman, D.A. A Modified Sectioning Search Approach to Aggregate Planning. Ph.D-dissertation, Yale University, 1972. 